ISSN: $1130-3743$

\title{
EL LEGADO DE WILHELM DILTHEY: LAS PEDAGOGÍAS CULTURALISTAS
}

\section{The legacy of Wilhelm Dilthey: the Culturalists Pedagogies}

\section{Le legs de Wilhelm Dilthey: les Pédagogies Culturalistes}

Juan Carlos Rincón VERdera

Universitat de les Illes Balears. Facultat d'Educació. Departament de

Pedagogia i Didàctiques Específiques. Cra. de Valldemossa, km 7,5. E-O7122

Palma de Mallorca. Correo-e: jcarles.rincon@uib.es

Fecha de recepción: marzo de 2009

Fecha de aceptación definitiva: julio de 2009

Biblid [(1130-3743) 21, 2, 2009, 131-164]

RESUMEN

Eduard Spranger, Herman Nohl y Wilhelm Flitner son herederos directos del espiritualismo, el psicologismo y el historicismo de Wilhelm Dilthey, elaborando, a partir de él, pedagogías de marcado carácter cultural. Todos ellos se propusieron reelaborar el cuerpo epistemológico de la pedagogía, siguiendo, para ello, la tradición racionalista, de corte neokantiano, propia del momento (primera mitad del siglo XX). Para Spranger la ciencia de la educación se reducirá a una pedagogía de la comprensión hermenéutica; su misión consistirá en tomar una realidad cultural históricamente heredada y someterla a conceptos ordenadores que permitan adoptar posicionamientos valorativos y normativos de actuación. Nohl, por su parte, entenderá la pedagogía como una teoría de la educación que deberá siempre contextualizarse históricamente por lo que jamás podrá tener validez general. Por último, Flitner considerará la ciencia pedagógica como un filosofar dentro de la circunstancia histórica, es decir, una estética de la educación. 
Palabras clave: Dilthey, Spranger, Nohl, Flitner, Ciencias de la Cultura, Ciencias del Espíritu, Pedagogías Culturalistas.

SUMMARY

Eduard Spranger, Herman Nolh and Wilhelm Flitner are direct heirs of the spiritualism, psychologism and historicism of Wilhelm Dilthey, whom they used as a starting point to elaborate trends in pedagogy of a marked cultural character. All of them proposed to redo the epistemological body of pedagogy, following for that purpose the rationalist tradition, of a neokantian nature, characteristic of the times (the first half of the twentieth century). For Spranger, education science would be reduced to a pedagogy of hermeneutic comprehension; its mission would consist in taking a reality culturally and historically inherited and subject it to ordering concepts that would allow the adoption of value judgements and standards of performance. Nohl, on the other hand, would understand pedagogy as a theory of education that should always be contextualized historically, and therefore could never have a general validity. Finally, Flitner would consider pedagogical science as a philosophizing within historical circumstances, that is, a kind of aesthetics of education.

Key words: Dilthey, Spranger, Nohl, Flitner, Sciences of the Culture, Sciences of the Spirit, Cultural Pedagogy.

\section{SOMMAIRE}

Eduard Spranger, Herman Nohl et Wilhelm Flitner sont héritiers directs du l'espiritualisme, du psicologisme et le historicisme de Wilhelm Dilthey, en élaborant, à partir de lui, des pédagogies de marqué caractère culturel. Tous ont été proposés de reelaborer le corps épistémologique de la pédagogie, en suivant, pour cela, la tradition racionaliste, de coupe neokantian, propre du moment (première moitié du siècle XX). Pour Spranger la science de l'éducation sera réduite à une pédagogie de la compréhension hermenéutique, sa mission consistera à prendre une réalité culturelle historiquement héritée et à soumettre à des concepts ordinateurs qui permettent d'adopter des positionnements de valeur et normatifs d'activité. Nohl, pour sa part, comprendra la pédagogie comme une théorie de l'éducation qui devra toujours être contextualisée historiquement ce pourquoi elle pourra jamais avoir validité générale. Finalement, Flitner considérera la science pédagogique comme un philosopher dans la circonstance historique, c'est-à-dire, un esthétique de l'éducation.

Mots clés: Dilthey, Spranger, Nohl, Flitner, Sciences de la Culture, Sciences de l'Esprit, Pédagogies Culturalistes.

\section{INTRODUCCIÓN}

El presente trabajo pretende ser un ejercicio de pedagogía histórica, es decir, un estudio histórico de las aportaciones culturalistas de Spranger, Nohl y Flitner a los procesos de epistemologización propios de la pedagogía contemporánea. 
Todos ellos son herederos directos del pensamiento espiritualista, psicologista e historicista de Wilhelm Dilthey, elaborando a partir de él pedagogías de marcado carácter espiritual y cultural ${ }^{1}$ (Geisteswissenschaftliche Pädagogik)2. En este artículo queremos hacer patente una forma de pensar, hacer y entender la pedagogía y su objeto de estudio, la educación. Aunque estas pedagogías supongan un modelo ya pretérito, no debemos olvidar, tal y como nos indica J. Sarramona (2000, 200), que los conocimientos educativos son acumulativos y difícilmente se puede considerar que alguno de ellos haya dejado de tener alguna vigencia en el conocimiento de la realidad educacional. Dicho todo ello, y antes de pasar a desarrollar el cometido de este artículo, apuntemos algunas notas fundamentales del pensamiento de Dilthey.

1. Los términos espíritu y espiritual han sido usados en varios sentidos y dentro de muy diversos contextos. En concreto nuestros autores se han preocupado por el concepto de espíritu objetivo, estando, con pequeñas variantes, en la línea de Dilthey. Dilthey está muy próximo al concepto hegeliano de espíritu objetivo, presentando, sin embargo, una diferencia fundamental, pues mientras para Hegel el espíritu objetivo es un camino racional hacia la suprema realidad del espíritu (espíritu absoluto), en Dilthey el espíritu es un único complejo, no inferido ni investigado por el pensamiento, sino vivido (vitalismo), punto de articulación de las vivencias individuales, históricas y sociales. Dilthey, en definitiva, en lugar de la razón universal hegeliana pone la vida en su totalidad, la vivencia, la comprensión, la conexión histórica de la vida con todas sus irracionalidades. En este sentido, en Dilthey las que denomina Ciencias del Espíritu son un grupo de ciencias caracterizadas por el método científico espiritual o método de validez universal que se sustenta en la psicología, pues permite comprender al hombre como entidad histórica, llegándose así a la objetivización ideal. Véase Ferrater (1979, 1015-1020).

2. Las Pedagogías Culturalistas o Pedagogías de las Ciencias del Espíritu (Geisteswissenschaftliche Pädagogik) suponen una visión filosófica (espiritual y antropológica) de la educación muy próxima al hombre, la vida y la historia (Álvarez, 2001, 65). Estas pedagogías se centran en la transmisión de los contenidos culturales vitales (espíritu objetivo) a las nuevas generaciones (espíritu subjetivo) para que éstas puedan recrear todo un mundo de significados culturales. Es la realidad cultural quien mejor puede formar a los educandos, de ahí, precisamente, que sea la comunidad de cultura (comunidad de significados) la encargada de transmitir los conocimientos necesarios para la adecuada formación de los futuros ciudadanos (Vilanou, 2002a). Ahora bien, la realidad cultural es el resultado de un proceso evolutivo histórico; solamente hay verdadera educación si se contextualizan históricamente los contenidos curriculares a transmitir. El método hermenéutico-interpretativo (comprensión histórica) es consustancial a estas pedagogías. La comprensión de los fenómenos educativos es la tarea científica que se le asigna a la pedagogía en tanto teoría del conocimiento educativo, con lo cual la Ciencia de la Educación acaba diluyéndose en una Filosofía de la Educación, en una idealización del hombre y su formación, alejándose, con ello, de la necesaria materialidad de la ciencia (Colom, 1978, 306). Por otra parte, podemos decir que la Pedagogía de las Ciencias del Espíritu fue, de alguna manera, la pedagogía oficial en Alemania durante los años de la República de Weimar (1919-1933), prolongándose a toda la primera mitad del siglo XX. La revista Die Erziehung (publicada en Leipzig desde 1925 bajo la dirección de Fischer, Spranger, Nohl, Flitner y Litt), actuó de portavoz de dicha pedagogía oficial. Esta pedagogía tuvo su máximo esplendor en el panorama pedagógico español hacia mediados del siglo $\mathrm{XX}$, desapareciendo con la llegada de la transición y el paso a la democracia. Hoy en día podemos decir que sus propuestas educacionales son desconocidas para las nuevas generaciones de pedagogos, formando parte, o quizás tampoco, del baúl de los recuerdos de una pedagogía de corte neoidealista, herencia directa del espiritualismo alemán de la época (Roith, 2006). Ver también: Goergen (1999), VILANOU (2002), Schriewer y E. KeINER (1997). 


\section{El PUnto de partida: la comprensión históRica en Wilhelm Dilthey}

La estructura interna del pensamiento de Wilhelm Dilthey ${ }^{3}$ se puede sintetizar en dos puntos: por una parte, la visión y comprensión de la vida como una totalidad (Ropero, 1999, 518-519; Urdanoz, 1978, 115-116); y, por otra, la historicidad de todas las producciones del espíritu humano, de todo el mundo cultural (Abellán, 1998, 347); mundo en el que se integra la educación y su ciencia, la Pedagogía (Dilthey, 1978a; Villalpando, 1976, 54). El objeto de las Ciencias del Espíritu (Geisteswissenschaften) es la realidad histórica y social (mundo histórico y cultural), que está formada por individualidades que sólo pueden ser conocidas por el método hermenéutico, el cual busca hacer comprensible la unidad estructural de la vida como un todo global (Dilthey, 1978b, 1978c). De partida debe quedar muy claro que el objeto de las Ciencias del Espíritu no es exterior al hombre, sino interior, captado a través de la experiencia interna del sujeto que conoce, con lo cual no puede ser alcanzado tan sólo a través de los procedimientos específicos de las Ciencias de la Naturaleza (Naturwissenschaften), sino que ha de contar, especialmente, con los instrumentos propios de las Ciencias del Espíritu. La comprensión (verstehen) es la operación intelectual de estas últimas ciencias, distinguiéndose de la explicación (erklüren), que es la propia de las Ciencias de la Naturaleza, porque explicar es establecer conexiones causales entre los objetos de la experiencia externa, mientras que comprender es una forma interna de simpatía empática con un hecho o acontecimiento histórico-cultural a partir de la vivencia personal de sus valores (Páez, 1988, 12; Zubiri, 1982, 247-248). El fundamento heurístico que despliega el sistema comprensivo del mundo cultural y espiritual, radica en la vivencia, la expresión y la comprensión, representativa del proceso reconstructivo de la experiencia creadora de una objetivación mental (Dilthey, 1978c).

Por lo tanto, el conjunto de lo vivido, de lo expresado y de lo comprendido es el método específico propio de las Ciencias del Espíritu. Estos tres momentos, fuertemente unidos, interrelacionados y recíprocamente condicionados, constituyen el andamiaje de las Ciencias del Espíritu (Rossi, 2006, 14-16):

- El sujeto humano, en su anhelo de conocer (conocimiento científico), parte de la contemplación y, a la vez, interiorización de las vivencias del mundo (erlebnis, vivencia o experiencia interna de la vida). La vivencia no es algo dado, sino que es cada cual quien penetra en su interior, quien la posee de modo inmediato (inmediatez o interioridad). Es más, el

3. Para una mayor aproximación a la filosofía de Dilthey, véanse las Obras completas de Wilhelm Dilthey (1978), en castellano (obra completa en 10 volúmenes), traducidas por Eugenio Imaz (México, FCE). Ver también Joan Roura-Parella (1947). En materia educacional ver el trabajo de Colom y Rincón (2004). 
sujeto que recupera su condición vital, su experiencia vivida, mediante la reconstrucción de su propio proceso histórico-vital, se configura en sujeto y objeto de sí mismo (Herrera, 2007).

- A continuación, por medio de sus acciones, en su relación con los sujetos y los objetos, y en sus diversas formas de expresión, el sujeto cognoscente plasma el significado que ha dado a sus vivencias interiorizadas (erleben, expresión o materialización de la vivencia del espíritu en la cultura).

- $\quad$ Por último, a partir de la experiencia vivida se reproduce lo que otro sujeto ha vivido, entendiendo las razones y el sentido de sus acciones, haciéndolas inteligibles (versteben, comprensión o identificación espiritual). La comprensión es un tipo de empatía, de tal manera que comprender a una persona (sus obras o acciones) en una situación particular (contextualizada), es poder revivir o reconstruir en uno mismo las vivencias ajenas. Desde esta perspectiva, la comprensión es el verdadero método para conocer, es el método fundamental para todas las operaciones de las Ciencias del Espíritu. Tal es así, que el conocer se justifica por su referencia a la vida anímica, tal y como se nos da en la vivencia y en la comprensión (Dilthey, 1978c, 339). La comprensión, por lo tanto, es el conocimiento psíquico subjetivo del otro a partir de signos externos, lo cual implica (Quintanilla, 2008, 116): revivir (nacherleben), reproducir (nachbilden) y transferir (hineinversetzen).

Como podemos ver, se trata de descubrirse en el propio vivir, donde no sólo existe el mundo interior del sujeto, sino todo un mundo exterior objetivado, en el que las Ciencias del Espíritu serán las encargadas de mediar, interpretar y comprender, es decir, de vivir, revivir, reproducir y transferir (Rumié, 2008). Desde esta perspectiva, podemos decir que las Ciencias del Espíritu no pueden existir sin referencia a la experiencia vivida, puesto que la vivencia de un individuo es lo que se comprende en el otro. Los hechos espirituales tienen un sentido, no son objetos naturales que puedan ser observados y experimentados y que, a través de la neutralización de la vivencia del observador, puedan ser delimitados secuencialmente como un conjunto atomizado de elementos. La comprensión se funda en la vivencia y ésta, a su vez, necesita de la comprensión (Díaz de Cerio, 1959, 522). La vivencia, la expresión y la comprensión, en último término, se dan dentro de la vida, siendo ésta el ámbito en cuyo interior se manifiesta toda la realidad espiritual y cultural. Desde el punto de vista de la epistemología diltheyana, la vida es saber y el saber es vida, con lo cual el sujeto que conoce, el acto de conocer y el objeto conocido son una y la misma cosa. El análisis de las Ciencias del Espíritu se convierte en el camino para llegar a la vida: se trata del mismo camino que la vida ha ido recorriendo en el curso de la historia y en cuyo trayecto ha ido dejando como indicadores sus objetivaciones culturales. Para comprender el mundo espiritual, histórico y cultural, será preciso hacer el viaje a la inversa y llegar, a partir de las manifestaciones de la vida, a la vida misma, 
a través de su vivencia y de su comprensión: la comprensión hermenéutica consiste en reconstruir en sentido inverso, de afuera hacia adentro, la vivencia original (Zamora, 2001, 49).

Como es evidente, la psicología explicativa de las Ciencias de la Naturaleza se opone, en el plano metodológico, a la Psicología comprensiva (Verstehende Psychologie), propia de las Ciencias del Espíritu, que se convierte en la ciencia modelo para el estudio e investigación del mundo espiritual (Dilthey, 1978d; López, 1990; Teo, 2003). Como hemos dicho, si las Ciencias de la Naturaleza proceden basándose en la explicación, es decir, estableciendo nexos causales, las Ciencias del Espíritu excluyen la causalidad, el atomismo y, consecuentemente, la explicación. Las Ciencias de la Naturaleza explican su fenomenología con leyes objetivas y causales, las Ciencias del Espíritu deben preocuparse más por aprehender los distintos sentidos y significados presentes en cada una de sus manifestaciones, es decir, deben ocuparse de la comprensión empática ligada siempre a los planes vitales, pretensiones, credos, apegos y afectos de los seres humanos, todo lo cual se da siempre contextualizado históricamente (Betancourt, 2006, 116). Los hechos psíquicos, tal como se dan en nuestra vivencia, no son agregados de elementos sino realidades integradas en un todo que no se puede fragmentar ni construir mediante procesos sintéticos. Lo que se comprende son vivencias significativas, entendiendo por significado la relación que dentro de la vida guardan las partes con el todo. Como vemos, el significado es una relación estructural, en virtud de la cual, la vida interior, en todas y cada una de sus manifestaciones, se presenta como un todo orgánico e integrado, en el cual sólo las partes individuales tienen posibilidad de realizar su realidad y asumir su valor específico (Martínez, 1989, 108-109).

No obstante ello, y en contra de lo que podría parecer, para Dilthey la explicación causal y la comprensión hermenéutica, lejos de oponerse en el plano epistémico, se necesitan mutuamente para entender y alcanzar la totalidad estructural del mundo espiritual, puesto que la vida entendida como un todo sistémico debe ser explicada y comprendida si no la queremos sesgar. Es más, Dilthey va mucho más lejos en sus planteamientos epistemológicos y acaba subsumiendo las Ciencias de la Naturaleza en las Ciencias del Espíritu (Cruz, 1991, 68), puesto que la realidad externa sólo se ofrece de modo conexo con el yo cognoscente, y únicamente encuentra explicación desde la experiencia interior de la conciencia subjetiva que conoce. Esto quiere decir que la naturaleza misma aparece situada en el nivel de la vida, con lo cual la hermenéutica tiende a cubrir todos los huecos existentes entre la explicación del mundo natural y la comprensión del mundo espiritual (Ferrater, 1949, 8-9).

Ahora bien, el inconveniente que se nos presenta ante tales planteamientos epistemológicos es que en el transcurso de la comprensión hermenéutica diltheyana la subjetividad no puede ser descartada, puesto que el sujeto cognoscente arrastra sus cosmovisiones, sus propias posiciones teóricas y prácticas, sus experiencias, sus expectativas, sus preocupaciones y sus reflexiones valorativas. La hermenéutica diltheyana sólo puede alcanzar el objeto del conocimiento según el modo actitudinal 
del sujeto cognoscente. La visión de un objeto, por lo tanto, lleva siempre la huella del sujeto que conoce y, consecuentemente, nunca puede ser enteramente neutral. Todo conocimiento es siempre un punto de vista, una perspectiva o interpretación subjetiva, una manera relativa de aprehender un objeto, el cual permanece inescrutable en su realidad propia. La metodología comprensiva de Dilthey, por lo tanto, es una interpretación subjetiva de la realidad, sometida al cambio temporal, espacial e histórico (Dilthey, 1978b, 137). De aquí que la visión de los objetos y del mundo no sólo no sea objetiva, sino que venga determinada por la historia, por el momento histórico de la misma, que irracionalmente determina la subjetividad (relativismo irracionalista). Así pues, en esta posición, la visión del objeto no sólo depende del sujeto, sino que, además, éste está sometido a un continuo cambio en relación con el momento histórico que le haya tocado vivir. El conocimiento, por lo tanto, no puede ser desinteresado ni neutro, sino que varía según el sujeto y su contextualización. Por eso la comprensión hermenéutica diltheyana, además de subjetivista, es historicista, relativista y, en su punto más extremo, escéptica: «[...] la relatividad de todo género de creencia constituye el último paso para la liberación del hombre" (Dilthey, 1978a, 318).

En este contexto de relativismo, teleología, perfección y desarrollo, es decir, tal y como nos dice Montovani (1997, 34), el paso del ser al deber ser, son las claves de la vida anímica en los planteamientos diltheyanos. En este paso de lo que somos por naturaleza (ser) a lo que debemos ser por moralidad (deber ser), la educación juega un papel estelar. La pedagogía, apoyada en la psicología comprensiva ha de dilucidar el camino que ha de seguir la educación para que el hombre se oriente perfectivamente, de acuerdo con los valores universales del conocimiento histórico (Dilthey, 1949, 57-58; Vilanou, 1998, 258). La educación, consecuentemente, será la actividad intencional (planeada) mediante la cual los adultos formarán la vida anímica de los seres humanos en desarrollo (todo lo axiológico orientado teleológicamente) con el objeto de mantener vivo en el pueblo, de generación en generación, el espíritu objetivo, es decir, la tradición cultural (Dilthey, 1949, 47-48; Sánchez y Ordóñez, 1997, 141). Así pues, en Dilthey la educación no puede ser (Quintana, 2000, 133) una simple conducción (fübren), ni tampoco un mero dejar crecer espontáneamente (wachsenlassen), sino que su objetivo debe ser un ideal mucho más elevado: introducir a los educandos en un universo de sentido cultural dado históricamente (Dilthey, 1957, 60). Consecuentemente, la vivencia y la educación serán la interacción de situaciones en las que el alumno está confrontado por una pluralidad de sentidos culturales posibles. Ahora bien, Dilthey diferencia los medios de la educación, que estarían dados por el conocimiento científico y se desarrollarían paralelamente a la ciencia, del fin de la educación, que remitiría a costumbres, ideales y medios de una sociedad (Dilthey, 1957, 14). Lo que realmente preocupa y ocupa a Dilthey no son los medios materiales de la educación, sino los fines espirituales y culturales de la misma (Rojas, 2006). Tal y como nos dice Vilanou (2001, 272), no basta conocer hechos y dirigirlos técnicamente, hay que tener encima de sí valores morales. 
Como podemos observar, para Dilthey, en clara oposición a los planteamientos herbartianos, no es posible una ciencia pedagógica con validez general que partiendo de los fines educacionales quiera extraer las normas y metodologías de actuación práctica (Dilthey, 1949, 154; Houssaye, 2003, 246). No es posible expresar en conceptos de validez general tendencias que surgen de lo más profundo del espíritu humano (valores que son ordenados por la inteligencia de acuerdo con la estructura teleológica de la vida). El fin último de la vida es una representación trascendental (ultramundana) que nunca puede ser expresada en conceptos de validez universal, y por ello la finalidad de la educación (el desarrollo de la vida anímica), tampoco puede ser reducida a ninguna fórmula ideal. Es más, sólo partiendo de la meta de la vida se pueden determinar los fines de la educación. Todo sistema histórico de la pedagogía que haya sido eficaz, nos dice Dilthey $(1957,31)$, ha estado condicionado por su proceso evolutivo, por su historicidad y, por lo tanto, tal y como ya habíamos anticipado, por su relatividad. Desde esta perspectiva, en educación lo máximo que puede hacerse es destacar un número limitado de principios universales a fin de derivar normas y reglas particulares de actuación para la vida; normas de acción que deberán adaptarse a las circunstancias históricas (Dilthey, 1949). La pedagogía, por lo tanto, tiene por objeto descubrir lo que es finalístico en el hombre, es decir, estudiar la estructura teleológica que da sentido a su vida; la conciencia de un fin en el proceso interno es lo que da unidad a la vida considerada como un todo orgánico. Este principio teleológico básico, que es, al mismo tiempo, principio vital, no es otra cosa que la conservación y exaltación de la especie humana y de todos y cada uno de sus miembros. La psicología comprensiva, la hermenéutica de la vida, ha de estudiar esta conexión teleológica y descomponer causalmente cada una de sus partes (explicación causal) para poder extraer normas que, no obstante, deberán ser contextualizadas históricamente o, si se quiere, experimentadas y demostradas a posteriori (comprensión hermenéutica). Dilthey, en última instancia, acaba subordinando la educación y su reflexión teórica, la pedagogía, a la misma vida, a una filosofía vitalista (lebensphilosophie) de corte histórico, subjetivista y relativista (Ferraris, 2002, 151; Brie, 2000).

\section{Eduard Spranger: la educación como transmisión CUltural en un CONTEXTO Ético Y LA PEDAGOGÍA COMO CIENCIA COMPRENSIVA DE CARÁCTER ESPIRITUAL}

Spranger entenderá que la misión de la educación debe ser la transmisión de la cultura que el educando recibe a través de su psicología y asume dentro de un contexto histórico, ético y cultural. La formación integral de los hombres se realiza en relación con los ideales histórico-culturales, por lo que la educación será una actividad eminentemente cultural, que se realiza por medio de la interrelación del hombre con los bienes culturales (Huergo, 2005). La pedagogía, por su parte, será una Ciencia del Espíritu (Ciencia Cultural), que deberá desembocar en una pedagogía de la comprensión hermenéutica. Su concepción pedagógica 
y educacional son inseparables de tres conceptos clave: espiritu objetivo (mundo cultural), la psicología comprensiva (hermenéutica) y la tipología bumana (tipo ideal de hombre).

\subsection{Espíritu objetivo, psicología comprensiva y tipología bumana}

Spranger, siguiendo a Dilthey, concibe la psicología como una Ciencia del Espíritu, es decir, como ciencia comprensiva de la realidad humana. Comprender (Spranger, 1966, 36) será descubrir, por parte del espíritu subjetivo (el hombre), el sentido de las formas del espíritu objetivo (arte, lenguaje, ciencia, religión, cultura, etc.). En este sentido, Spranger $(1947,56)$ nos dice que algo está provisto de sentido si contribuye a la realización de valores culturales, es decir, si está integrado en un todo axiológico como elemento constituyente: "[...] tiene sentido lo que en un todo lógico (sistema de conocimiento) o en un todo de valor (sistema de valor) entra como miembro constitutivo obedeciendo una ley, de constitución particular" (Basave, 1968, 52). Desde esta perspectiva, el espíritu objetivo será el conjunto global de todas las realizaciones humanas repletas de valores supraindividuales ligadas al mundo cultural y espiritual. La comprensión es el descubrimiento del sentido de las formas del espíritu objetivo que sólo puede ser objetiva cuando se refiere y se fundamenta en valores objetivos. La misión de la psicología (psicología comprensiva) será estudiar la estructura de la vida anímica en su relación con la esfera objetiva de los valores, única forma de entender y comprender las peculiaridades de los hombres. Además, la psicología no debe limitarse a un análisis de los actos espirituales, sino que debe abarcar, en unidad indisoluble, estos actos y el mundo incluido en ellos, en su referencia al universo de los valores. Así pues, la psicología es la ciencia del sujeto individual que no puede ser separado de sus relaciones objetivas: sujeto y objeto sólo pueden ser pensados en relación mutua (Hohmann, 1996).

Pues bien, según Spranger (1947, 27-28), cuando en este estudio comprensivo se acentúa el aspecto subjetivo individual se trata de psicología y se ocupa, en primer término, de las vivencias que surgen de la relación del sujeto con lo transubjetivo y colectivo; y, en segundo término, investiga también los actos que van de acuerdo con las leyes crítico-objetivas. Para Spranger, por lo tanto, sólo puede hacerse psicología en la más íntima conexión con la ciencia objetiva del espíritu, tanto la histórico-descriptiva como la crítico-normativa. Desde el momento en que la psicología del conocimiento presupone alguna teoría concreta del conocimiento, la psicología, ahora entendida globalmente, presupone la actitud comprensiva propia de la Ciencia del Espíritu, con lo cual lo subjetivo ha de destacar siempre por encima de lo objetivo. A esta psicología la llama Spranger psicología mental o psicología de las estructuras (psicología comprensiva) que, según él, supera definitivamente la psicología naturalista de corte mecanicista (ibidem, 30; Fierro, 1993, 102). Como veremos a continuación, y siguiendo en ello a Dilthey, lo peculiar de los hechos psíquicos está dado por las conexiones de sentido y significado. Este 
atributo no es cuantificable ni traducible a indicadores empíricos, en consecuencia, no puede ser ni siquiera planteado por una psicología de carácter naturalista. Si se despoja a lo psíquico de esta cualidad, el concepto mismo de lo psíquico se presenta como un dato vacío de contenidos.

Esta psicología comprensiva parte de la totalidad de la estructura psíquica, entendiendo por estructura una conexión de funciones, y por función, la realización de lo que se ajusta al valor objetivo. Ahora bien, en la estructura total de la espiritualidad humana se insertan, a su vez, estructuras parciales con plenitud de sentido, como la estructura del conocer, la del trabajo técnico o la de la conciencia específicamente religiosa. Allí donde se observa la acción conjunta de las estructuras totales o parciales de distintos sujetos y se produce una objetivización transubjetiva, surge el espíritu colectivo (Hohmann, 1996, 125). Si son, además, legítimas, es decir, si se ajustan a la norma (moral), sirven de fundamento al espíritu objetivo en sentido crítico, cuyo contenido espiritual será accesible a toda conciencia capaz de colocarse en la situación concreta que le sirve de base. Así pues, sobre el yo limitado y contingente se erige un mundo espiritual de sentido supraindividual que se desarrolla históricamente, sufriendo transformaciones y, en determinadas circunstancias, puede acabar por decaer y declinar (Kerschensteiner, 1926, 79; Vilanou, 2004, 50). Esta psicología tendrá por cometido romper el aislamiento del individuo y comprenderlo en la complejidad y concreción viviente de todas sus relaciones, tanto con los otros sujetos como con los objetos de la realidad (Spranger, 1966, 30-45). La aplicación de estas premisas da como resultado una ciencia sistemática de las manifestaciones individuales y sociales de lo humano y, como paso previo, una tipología de las individualidades o formas de vida representantes de un sector cultural predominante (ibidem, 1617). A este proceder, Spranger lo denomina típico-ideal y, básicamente, consiste en la observación, en su singularidad, de los fenómenos psíquicos, que repletos de contenidos procedentes de la historia de la cultura, se idealizan después para poderlos explicar desde una doble dimensión totalizadora e individualizadora (Scheler, 1998, 60).

Será a la morfología de la cultura y su historia, nos dirá Spranger $(1947,57)$, a quien corresponderá indagar cuál es el centro ideal, ético y religioso, que se erigirá en el marco rector de dichos contenidos culturales: «[...] el hombre necesita para formarse del trato con las condiciones históricas de la cultura" (Taborda, 1951, 295). A partir de aquí surge la necesidad de establecer unos tipos bumanos ideales, o esquemas generales de entendimiento de la conducta humana, capaces de dar sentido totalizador a la misma y de explicar, en lo concreto, las motivaciones de los actos singulares (Spranger, 1946). Esta tipología, al determinar los tipos humanos ideales posibles, permite: por una parte, comprender mejor los tipos humanos mixtos realmente existentes (tipos principales de estructura psíquica); y, por otra, descubrir las diversas formas culturales que se han dado en la historia de la humanidad (espíritu objetivo), y que la educación deberá transmitir, en cada caso, a las jóvenes generaciones. A cada clase de acto o vivencia humana le corresponde una esfera 
de sentido en el marco cultural (Iglesias, 2007, 82). De este modo, investigando las clases de valores se puede también indagar las clases de actos humanos, en tanto que cada uno de ellos posee un sentido totalizador fundamentado en un valor cultural individualizador y específico. En todo acto humano con sentido están contenidas, simultáneamente, todas las formas fundamentales de actos de la misma clase: en todo acto espiritual actúa la totalidad del espíritu, ya que las esferas de la cultura se insertan unas con otras mediante conexiones funcionales de carácter estructural.

A partir de aquí, tal y como podremos observar, la división tipológica ${ }^{4}$ que del ser humano realiza Spranger será la resultante de la diversidad de actitudes asumidas por la persona frente a los valores fundamentales de la cultura (Spranger, 1966, 66; Fierro, 1993, 102); es decir, su clasificación atiende a los principales valores o actitudes valorativas que caracterizan y dirigen la conducta personal de los individuos (Vidaña, 2007, 6-7). Fundamentalmente señala seis tipos ideales ${ }^{5}$ (Spranger, 1966, 155-231):

- Hombre teorético. Su interés reside en el conocimiento por el conocimiento antes que en la especulación o aplicación práctica de los mismos. Esta condición implica un interés absoluto en la búsqueda de la verdad, predominando la actitud cognoscitiva, que debe estar presidida por la

4. Los actos humanos individuales con sentido, según Spranger, son de cuatro tipos (SPRANGER, 1946, 55-78): 1) Actos Teóricos. Aquellos cuyo sentido radica en la identidad general del objeto aprehendido, en su esencia y en su dirección a lo objetivo-general. 2) Actos Económicos. Los que su sentido reside en la vivencia de la relación psicofísica de energía entre sujeto y objeto, en dirección cuantificadora del gasto o ahorro de dicha energía. 3) Actos Estéticos. Son los que tienen el sentido dirigido hacia el carácter de impresión-expresión de su apariencia concreta o imagen. 4) Actos Religiosos. Aquellos cuyo sentido está en la referencia de la vivencia singular al sentido total de la vida individual, dirigidos al valor total del individuo. Estos actos están gobernados por lo que Spranger (ibidem, 89) llama las leyes del espíritu, que son normas que rigen el funcionamiento de los fenómenos psíquicos desde su estructura finalística: 1) La ley de la economía (principio del mínimo esfuerzo); 2) La ley estética (principio de la forma); 3) La ley de la ciencia (principio del fundamento); 4) La ley de la política (principio de la voluntad jurídica y reguladora); 5) La ley de la sociedad (principio de la fidelidad); y 6) La ley de la religión (principio de la moral acerca de cómo ha de pensar y actuar el hombre de un modo unitario).

5. Eduard Spranger describe una tipología basada en los valores centrales que buscan las personas de acuerdo a sus características. La personalidad se estructura, según Spranger, sobre un valor central típico: en cada persona reside un valor específico que busca expresarse y cuya vivencia dota de sentido a la vida. Así, la búsqueda del conocimiento, la utilidad, la belleza, la solidaridad, el liderazgo o la espiritualidad son los ejes axiológicos sobre los que se configuran las personas. Aclaremos, sin embargo, que Spranger clasificará a una persona de un modo u otro en función de sus intenciones o actitudes, no de sus logros en un determinado campo, es decir, no considera necesario un grado muy elevado de talento, conocimiento o triunfos personales para clasificar a una persona en una categoría u otra. Además, la clasificación no incluye valores de carácter menos elevado y de índole más sensitiva. El mismo Spranger $(1966,425-451)$ advertirá que muchas personas no son ejemplos puros de ninguno de estos tipos, sino que denotan una mezcla de varios de ellos, es decir, una tipología mixta, que suele ser la realmente existente. 
objetividad como valor, lo que significa que los datos del objeto del conocimiento deben estar desprovistos de cualquier subjetividad. Su finalidad, consecuentemente, es la ley general objetiva, la verdad imparcial y el conocimiento verdadero, concibiendo el mundo y la realidad como un sistema de esencias universales y relaciones de interdependencia que deben ser ordenadas, sistematizadas y fundamentadas.

- Hombre económico. Asume un interés preponderante por lo que es práctico, siendo la utilidad el criterio fundamental de su actuación. Así pues, su interés por las cosas se deriva de su aprovechamiento práctico y utilitarista, asimilando lo verdadero a lo útil y lo falso a lo inútil. No busca, consecuentemente, el conocimiento por el conocimiento, sino su aplicación o explotación práctica, de ahí que esté muy interesado por el conocimiento tecnológico. Sólo le importa su vida y su negocio y, en consecuencia, es un defensor a ultranza de la propiedad privada como fundamento esencial del orden social. En este sentido, su sociabilidad es más aparente que real, porque su auténtico motivo no es el otro como un igual, sino el interés, la utilidad y la aplicación. Al igual que el político, como veremos, considera el poder como un valor, si bien asociándolo a la riqueza y al prestigio. En este sentido, todo tiene un precio y, por lo tanto, todo puede ser vendido o comprado a voluntad en el libre mercado.

- Hombre estético. Su actitud es puramente desinteresada y de contemplación psíquica, prestando y ofreciendo sentimiento a todo y transformando todas sus impresiones en expresiones. Sus valores residen en el terreno estético, juzgando sus experiencias desde una perspectiva simétrica y proporcionada, estimando lo que concierne a formas y armonía. No es necesario que tal individuo sea un creador, basta con que su interés se centre en el aspecto estético de la vida. Por lo general, si bien no es un tipo asocial, la individualidad es algo propio de su carácter, con lo cual en él no impera el deseo de ser útil a los demás, sino que los demás se convierten en objeto de goce estético. Rechaza toda ciencia que destruya lo intuitivo, sintiendo aversión por lo abstracto y lo conceptual. La naturaleza la concibe orientada desde ideas animistas y mitológicas, de aquí que muchas veces aparezca y se exprese como un romántico visionario. La religión del estético es la belleza, su dios es la suprema energía ordenadora y su carácter el animismo.

- Hombre social. Considera a las demás personas como fines en sí mismos $\mathrm{y}$, consecuentemente, tiene una manifiesta tendencia a adoptar puntos de vista altruistas y filantrópicos. Presenta, por lo tanto, una clara afirmación por los valores hacia la vida ajena y el sentirse a sí mismo en los demás (empatía), descartando cualquier acto social basado en la reflexión 
racional práctica (el ser humano como medio). Considera que el amor a la humanidad es la única regla que rige las relaciones humanas plenas. En este sentido, podemos decir que carece de contenido propio, apareciendo las demás esferas de sentido valorativo como contenido manifiesto de su existencia (se realiza en la entrega a los otros). De esta manera se opone al hombre teórico ya que éste considera la ciencia como motivo de orgullo y, por lo tanto, opuesta al amor. Se opone, también, al hombre económico y al hombre político, dado que no le interesan ni la utilidad ni el poder. Sin embargo, se relaciona mucho con el hombre religioso puesto que la comunidad se vive como totalidad.

- Hombre político. El motivo fundamental que da sentido a su conducta es el poder, entendido como capacidad de imponer a los demás la propia orientación valorativa. Aunque se interesa por las relaciones sociales, sustituye el concepto de amor por el de poder. Posee sentimientos de afirmación de la propia esencia, así como vitalidad y energía de la existencia, estando su vida impregnada por relaciones de poder, competencia y rivalidad. Los términos claves de su filosofía son la utilidad y la lucha. Su comportamiento se caracteriza por un deseo de poder personal y de influencia estratégica sobre los demás. En su extremo, el fin justifica los medios, teniendo un fuerte sentimiento de autoafirmación. Desde esta perspectiva, pone al servicio de su voluntad de poder todas las esferas de valor de la vida, convirtiéndose el hombre, incluso, en un medio instrumental para conseguir sus fines. Así pues, el ser humano es un medio nunca un fin que, en el caso más favorable, lo será para su propio bien.

- Hombre religioso. Es el que experimenta su vivencia de valor en su significación e importancia para el sentido total de la vida. El sujeto busca incesantemente alguna significación última a la vida o a la unidad mística con el cosmos. La religiosidad, el encuentro con Dios, da sentido a la totalidad de su vida. Dios es considerado como el principio objetivo que es pensado como objeto de la suprema experiencia personal de valor y, con ello, la religiosidad no es otra cosa que la búsqueda del supremo valor de la existencia espiritual del hombre. Existen tres formas de manifestación de la religiosidad: la primera, la del místico inmanente, cuando el modo en que los valores vitales particulares se relacionan con el valor total de la existencia tiene un carácter positivo; la segunda, la del mistico trascendente, cuando la relación entre lo particular y lo universal es negativa; y, la tercera, la naturaleza religiosa escindida, cuando la relación es mixta. Para el místico inmanente todos los valores positivos de la vida son gérmenes de lo divino y universal; para el trascendente todo lo humano carece de valor porque no es posible explicar lo divino si no es a través de lo revelado, por lo tanto rechaza lo útil, asume 
la mortificación y el sacrificio y desvaloriza su yo; por último, para los de naturaleza mixta lo fundamental es la fe o capacidad para confiar en lo divino (providencia) como determinante y explicador de los actos humanos. Las motivaciones generales del hombre religioso radican en la fe, sin poder precisar la frontera entre lo que esa fe supone de saber o de creencia. Otro motivo es su conciencia de trascendencia, que se explicita en su tendencia a rebasar lo finito, buscando objetos infinitos, aquellos que superan las normas del riguroso conocer, siendo sólo accesibles mediante la actitud religiosa.

Esta tipología nos acaba por conducir a la esfera de lo moral porque ésta no es, para Spranger $(1964,102)$, algo separado de las otras esferas de la vida, sino una forma general de ella que se manifiesta en todas las otras parcelas. Su concepción de la Ciencia del Espíritu conduce hacia una axiologia, hacia una filosofía de los valores que se concretará en una ética particular. La forma característica en la cual el valor objetivo se presenta a la conciencia es la experiencia del deber. De ahí, precisamente, que el criterio de lo moral, en caso de conflicto, sea el carácter normativo que presenta el valor superior. La ética tiene un esencial carácter de obligación incondicionada (Spranger, 1966b, 38): "[...] lo objetivamente valioso en una cultura es que ha de ser pensada como cumplimiento de normas de valor, como resultado de una ley valorativa que se presenta a la conciencia individual como exigencia, si no va con ella de acuerdo por sí misma". Este valor objetivo será el objeto de transmisión de la educación, mientras que la pedagogía será la forma comprensiva de interpretar lo educacional como un acto espiritual de carácter ético y moral.

\subsection{La educación como acto cultural y la pedagogía como comprensión bermenéutica}

En este marco de consideraciones valorativas y relativistas, la educación ocupará un puesto central, siendo su principal función la transmisión de la cultura que el alumno deberá asumir dentro de un contexto ético (Vázquez-Prada, 1972). La cultura es todo el complejo de valores dotados de significado y validez supraindividual que posee una sociedad concreta, históricamente desarrollada. La cultura, no obstante, para ser verdadera y viva precisa desembocar en la religiosidad, pues si la cultura no se remite a la fuente última de las convicciones humanas más profundas, nos dirá Spranger (1949, 105-106), decae hasta desaparecer. La educación, por su parte, es la actividad cultural dirigida a la formación de sujetos en trance de desarrollo, que se realiza mediante los auténticos contenidos de valor del espíritu objetivo, y tiene por finalidad el alumbramiento del espíritu normativo autónomo (Dri, 1966, 82). El proceso educativo se verifica en las auténticas sustancias de valor del espíritu objetivo (valores culturales). Por lo tanto, la educación será aquella actividad cultural dirigida a la formación personal de sujetos en desarrollo o, lo que 
es lo mismo, la voluntad despertada en el alma del otro, por medio de un amor generoso, para desenvolver, desde dentro, su total receptividad para los valores culturales (Spranger, 1966b, 449-453).

La educación se realiza por medio de los bienes culturales, que entonces se convierten en bienes formativos (Bildungsgut). Los bienes de formación o, mejor dicho, los valores de formación son los que constituyen el cuadro o conjunto de materias y actividades de enseñanza (currículum). El ideal de cultura y de comunidad cultural se convierte, también, en ideal de educación cuando se refiere a la formación personal (Bildung) de las nuevas generaciones. En definitiva, toda la estructura cultural se transforma en una estructura educativa cuando se refiere a la formación personal de los educandos (Spranger, 1966a, 147-148). Así pues, la educación se mueve siempre del valor objetivo de la cultura a la subjetiva receptividad de los valores culturales por parte de los sujetos educandos (transformar la cultura objetiva en cultura subjetiva o, dicho de otro modo, hacer vivir la cultura en los educandos), siendo la formación el principal proceso educacional (Spranger, 1947, 69; Ali Jafella, 2006, 152). Ahora bien, la educación no debe consistir, únicamente, en la simple transmisión del patrimonio cultural objetivo, históricamente dado, de la vieja a la nueva generación. La educación ha de procurar también el desarrollo del espíritu objetivo en sentido críticonormativo, es decir, ético-moral. En educación no puede tratarse sólo de introducir en la comprensión de los educandos la cultura dada, pues entonces sólo sería un medio de eternizar las relaciones existentes, con sus defectos y limitaciones (mera reproducción). No se trata, por lo tanto, de transmitir un sentido de la vida y de la cultura ya terminado y establecido (cosificado), sino de la búsqueda del sentido supremo de la cultura para que ésta llegue a ser una creencia en el alumno en desarrollo (Spranger, 1966b, 452-453). En definitiva, la educación tiene la función de proseguir la tradición cultural, pero también de avivarla espiritualmente: la esencia de la educación es vivificar de manera personal la cultura (Merino, 2005, 236).

El proceso educacional, Spranger considera cuatro factores fundamentales (Spranger, 1949, 26-27; Montes, 2003, 268-269):

- Los tipos ideales de formación. La teoría del ideal de formación parte de los tipos fundamentales eternos a los que se pueden reducir los ideales dados históricamente (tipología humana pura descrita anteriomente). Seguidamente se estudian las formas fenoménicas condicionadas por la historia en la que los tipos fundamentales se mezclan de múltiples modos y se configuran concretamente (tipología humana mixta). Por último, sobre la base de estas ideas, se critican los ideales de formación que surgen de la vida del presente, determinando la medida de su validez normativa mediante una consideración individualizadora de las condiciones culturales y personales de los sujetos educandos (contextualización). 
- La educabilidad. La teoría de la plasticidad de Spranger (la psicología pedagógica) tiene como supuesto una psicología evolutiva de la juventud (Saavedra, 2004, 13-14), que comprende, también, las diferencias psíquicas individuales (Spranger, 1935). Con sus resultados se enlaza la investigación de los métodos de educación y enseñanza. Esta didáctica está determinada: por una parte, por el contenido de los bienes culturales, por lo tanto, por una ley de la teoría del conocimiento (epistemología) y de los valores (axiología); y, por otra parte, por las formas psicológicas de apropiación (el proceso interno de la educación o teorías del cómo aprenden los niños). A este complejo pertenece también, como un método especial, no como un dominio particular, la pedagogía experimental, cuyos objetos de investigación se reducen a los medios pedagógicos, es decir, a las metodologías o didácticas.

- El educador. El tipo del formador de hombres muestra una forma de vida espiritual peculiar, muy parecida a la del hombre social y a la del hombre estético, sustentada por el amor, por el eros pedagógico. Efectivamente, el educador pertenece a un tipo humano social cuya esencia es un doble amor (Spranger, 1958; Gimeno, 2007, 19): por una parte, el amor a los valores espirituales; y, por otra, el amor a las almas en desarrollo, en las que se presienten posibilidades productivas de valores. El educador debe hacerse, debe formarse y madurar adecuadamente en el amor a los valores y al hombre, tomando conciencia de la responsabilidad que le incumbe en el ejercicio de su función (Vergara, 1970). Para el cumplimiento adecuado de tal cometido, Spranger señala la necesidad de una especial llamada, de un don particular o soplo espiritual que empuje a la acción formadora de otros, es decir, estar dotado vocacionalmente hacia la tarea educante. La meta fundamental de todo educador debe ser salir al encuentro de lo humano en toda su plenitud, siendo su función básica la transformación de los bienes culturales en bienes formativos, ordenándolos didácticamente para que el alumno los pueda recepcionar de manera adecuada (Spranger, 1966b, 449-454).

- La comunidad educativa. La comunidad de formación y la organización cultural, por último, deben ser objeto de la sociología pedagógica, que debe ser tratada como una parte de la sociología general, y no sólo metodológicamente, sino también en cuanto a las formas de la libre comunidad formativa y de la organización cultural, pues ambas son enteramente dependientes de la estructura general de la sociedad en que se encuentran incluidas.

La pedagogía, por su parte, deberá desembocar en una pedagogía de la comprensión hermenéutica de los acontecimientos educacionales históricamente considerados. El antagonismo de los poderes espirituales, que nacen de la vida popular, exige un poder espiritual superior, colocado por encima de ellos, mediante 
el cual se actualicen según su valor. Ahora bien, esto no es posible sin llevar la ciencia más allá de la mera realidad material, hasta la gran potencia ordenadora, formadora y conciliadora que reside en la reflexión espiritual, es decir, a través de una pedagogía científica de carácter hermenéutico (Spranger, 1949, 23). Hemos dicho que la pedagogía es una Ciencia del Espíritu. Pues bien, en tres planos se manifiesta el espíritu (Spranger, 1946, 319-332; Roura-Parella, 1935, 15): el primero, el plano subjetivo o la vida humana, en cuanto sucesión de estructuras estudiadas por la psicología (psicología comprensiva que culminará, como hemos visto, en una tipología organizada en torno a seis formas de vida primarias); el segundo, el plano objetivo o el conjunto de bienes culturales producidos por el hombre a lo largo de su desarrollo histórico (bienes materiales y espirituales); y, el tercero, el plano normativo o el campo propio de la ética, ya que la cultura puede ser juzgada según valores morales que nos indican pautas de actuación (valores morales que podrán ser individuales o socioculturales). La misión de la pedagogía científica estriba, pues, en tomar una realidad cultural ya dada, históricamente heredada, y someterla a conceptos ordenadores que permitan adoptar posicionamientos valorativos y normas éticas de actuación (Spranger, 1949, 223-225; Iglesias, 2007, 300).

Consecuentemente, la labor de la pedagogía comprensiva se desarrollará a través de tres grandes momentos o pasos secuenciales (Spranger, 1949, 23; Quintana, 1994, 120): 1) Momento descriptivo. La observación y descripción de todas las conexiones múltiples, buscando las relaciones funcionales de dependencia que existen entre cultura y educación; 2) Momento comprensivo. Descomposición de las estructuras complejas del mundo espiritual-social, tarea que no puede llevarse a cabo sin conceptos y puntos de vista directores, pues sin la base de una interpretación comprensiva y espiritual no se logra la descripción explicativa. Bajo su influjo se configura el material bruto hasta formar una totalidad sometida a leyes, las cuales, mediante un proceso de aislamiento e idealización, darán lugar a distintas tipologías o formas puras educativas en las que se descubrirán y comprenderán las estructuras ideales de la realidad educacional (Roura-Parella, 1935, 18); y, 3) Momento normativo. Campo normativo de los valores que proporcionará modelos de actuación educacional. Si los dos primeros momentos, el descriptivo y el comprensivo, significan una posición puramente teorética de la que nace una conciencia cultural, en el tercer momento, en el normativo, por negación del primer momento y afirmación del segundo, resurge el hombre vivo en el que la voluntad valorativa se eleva sobre el mero hacer, constar y registrar. Estamos, por lo tanto, ante el verdadero momento pedagógico.

4. Herman Nohl: la educación como aspecto. El aspecto subjetivo de la cultura y la PEDAGOGÍA COMO LA TEORÍA COMPRENSIVA DE LA EDUCACIÓN

Herman Nohl, en la misma línea que Spranger, entiende la realidad educacional como un todo cultural con sentido pleno. Sin cultura no hay educación, pero sin educación tampoco puede haber cultura. Por lo tanto, educación y cultura, 
cultura y educación, son las dos caras de una misma moneda que se necesitan irremisiblemente. La educación, en definitiva, es el aspecto subjetivo de la cultura. La pedagogía, por su parte, será la teoría comprensiva de la educación, la cual deberá siempre contextualizarse históricamente, por lo que jamás podrá tener validez general.

\subsection{La comunidad educativa como comunidad de cultura: la relación pedagógica basada en el amor}

Nohl, en la misma línea que los autores precedentes, está más preocupado por los grandes fines educacionales que no por los medios materiales de la educación. En este sentido, el fin de la educación es formar una vida espiritual unitaria, la cual sólo puede conseguirse por una acción educadora unitariamente espiritual (Nohl, 1968, 73). En este sentido, el hombre estará educado cuando toda su vida esté unificada por un ideal que, a su vez, no necesite de otro fundamento que una determinada posición valorativa frente a la totalidad del universo. Ahora bien, la educación no debe partir nunca de un sistema de valores dados (apriorísticos), sino de un yo originario, de un hombre real, con la firme voluntad de formar en él su plena personalidad moral. La educación, consecuentemente, es un acto íntimo y empático, vive en el individuo y desarrolla en él fuerzas y capacidades que le ayudarán a desarrollar su moralidad y a cumplir su destino espiritual (integrarse en una comunidad cultural que enriquecerá y de la que se enriquecerá espiritualmente hablando). Por lo tanto, la educación no puede ser independiente de la forma de existencia concreta de los educandos, pues la educación fuera de la comunidad cultural es algo abstracto, carente de sentido. No obstante ello, el educando no debe ser un sujeto pasivo que se tiene que adaptar a las finalidades de las viejas generaciones, imponiéndole las formas objetivas de la cultura heredada. El sujeto de la educación debe ser considerado en su propia vida espontánea productiva, tiene sus fines en sí mismo (Guardini, 2002, 56). El educador ha de desarrollar su tarea educadora centrada en el niño, sólo después se ajustará a los fines objetivos que le marca la comunidad de cultura (ambiente cultural de cada momento histórico).

Para Nohl, la cultura y la comunidad cultural son valiosos en cuanto que son producto de una vida espiritual, no como un contenido que, una vez recibido, produciría dicha vida espiritual. En este sentido, toda forma educativa es educación individual no sólo respecto al educando, sino también respecto a la comunidad cultural como unidad espiritual total. El fin educacional debe ser la formación del hombre, y con él el desarrollo de la comunidad cultural, hacia una vida espiritual sana y noble. Los fines objetivos aparecerán pedagógicamente justificados cuando su contenido y su estructura den a la vida individual su contenido y su forma suprema (Nohl, 1968, 36-37). La fuerza fundamental de la vida educacional consistiría: de un lado, en el yo que se desarrolla por sus propias fuerzas y que tiene su fin en sí mismo (valor individual); y, de otro, en los grandes contenidos 
objetivos de la educación, la conexión de la cultura y las comunidades culturales que tienen exigencias respecto a este individuo (valor comunitario y cultural). El educando es un fin para sí mismo y para la comunidad cultural (Nohl, 1965, 263278; 1968, 39): también está obligado respecto a la estructura y fines objetivos para los cuales es educado (configurar las fuerzas vitales del individuo de modo que integren de modo unitario las formas de la cultura objetiva). La educación debe formar al hombre en lo personal y en lo sociocultural. Este segundo plano, sin embargo, se levanta, necesariamente, sobre el plano individual (Nohl, 1968, 3738). El punto de partida es el sujeto individual que educaremos para integrarlo en la comunidad cultural. El valor de este ideal, consecuentemente, derivaría no de sus contenidos, sino de la unidad interna que haya entre ellos (Artigas, 1956, 77).

El proceso espiritual se fundamenta en el hecho de que desde el fondo vivo del sujeto, en su coexistencia con otros sujetos (ser con otros), surgen formas que, siendo en sí significativas y válidas, llegan a convertirse en normas de vida (el arte, la ciencia, el derecho, la religión, la moralidad, etc.), las cuales se separan del sujeto y alcanzan una existencia propia y una autoridad independiente (espíritu objetivo). La cultura se ha objetivado y se presenta frente a los sujetos, que deben servir ahora a su obra, difundiéndola y preservándola, lo cual no es posible sin la participación activa de la educación. La cultura sólo perdura cuando es alimentada constantemente por la fuente del sujeto que la vive y la recrea. Si esta corriente se interrumpe, separando la cultura del sujeto que debe vivirla, aquélla acaba por morir (Nohl, 1968, 38). Toda la vida está atravesada por el intercambio cultural y por la guía espiritual, con lo cual en cada circunstancia vital hallaremos un momento social y culturalmente educativo (Ortega, 2005, 117). De hecho, tal y como afirma Nohl $(1968,66)$, la vida es la gran educadora puesto que el hombre se realiza (se hace) en la actuación vital de cada día con los sujetos y los objetos de la realidad vital (realidad vital que es histórica). La educación y la instrucción aparecen, desde esta perspectiva, sólo como medios particulares junto a otros en el trabajo educativo, en el cual se realiza el desarrollo y la formación tanto de la comunidad como de los individuos. Ahora bien, desde el punto de vista estrictamente pedagógico y educativo, sólo podemos hablar de actuaciones educativas cuando el intercambio educacional se realiza con la voluntad consciente de ser una guía para la formación de los educandos (acción intencional, planificada y sistemática), para lo cual se procura sus propios medios, procedimientos e instituciones educativas (Nohl, 1965, 41). En este sentido, el fundamento de la educación lo constituye la comunidad educativa (comunidad moral y vital) entre el educador y el educando, con su intencional voluntad de formación e instrucción, desarrollándose en espacios específicamente escolares (ibidem, 43-44).

Como ya habíamos anticipado, el fin de la educación es despertar al educando a una vida espiritual unitaria, lo cual sólo es posible en el seno de una vida espiritual unitaria (Nohl, 1965, 28). La gran unidad de la educación es el carácter pleno de sentido en su totalidad unitaria, dependiente de la constitución histórica de una época. A la vez, cada individuo contribuye a la construcción de ese todo 
cultural educativo en la medida en que tiene la firme voluntad de formarse de acuerdo con dicho espíritu de la época (Nohl, 1968, 115-116). El efecto pedagógico no parte, como ya hemos anticipado, de un sistema de valores válidos, sino de un yo originario, de un hombre real con una firme voluntad, que está dirigida también a un hombre real, es decir, la formación desde una unidad espiritual (Nohl, 1965, 44). Nuestra disposición nos conduce a los objetos, pero la relación educativa (Espino, 2004, 215) forma también la disposición, y la forma, no por los objetos en sí, sino por las energías personales a las que pertenece también la objetividad. Desde esta perspectiva, el fundamento de la educación será la relación afectiva (amorosa e interpersonal) de un hombre maduro (educador) con un hombre en desarrollo (educando) por él mismo, para que éste llegue a su vida y a su forma (paso del ser al deber ser) acorde con el espíritu unitario de la época. Para Nohl, la relación amorosa permite saber que se está en el buen camino, en el camino de la verdad con todas sus consecuencias (Rosales, 1959, 37). La relación específicamente pedagógica (educador-educando), por lo tanto, será un comportamiento espiritual de un género independiente que se dirige al hombre en desarrollo como consecuencia de su forma superior de vida (Nohl, 1968, 46; Valenzuela, 2004, 53).

La relación del educador con el educando está siempre determinada por el amor hacia éste en su realidad concreta, y por el amor a su fin educacional, es decir, al ideal del niño. El ideal es fuerza motriz, pertenece al campo de la imaginación simbólica (idealidad), que, no obstante, no se opone a la racionalidad (realidad), sino que la engloba, la precede y la trasciende (Savater, 1994, 45). Para Nohl es la combinación de una visión idealista con otra realista la que constituye la esencia de la relación educativa (Bollnow, 1979, 51-52). Ahora bien, ambas cosas, realidad e idealidad, no son aspectos separados, sino un todo espiritual unitario (Nohl, 1965, 48). El fin pedagógico no es adiestrar para un tipo de vida, sino conseguir su ideal de vida espiritual, hacia el que debe orientarse el amor pedagógico (relación educativa). No se debe presentar nada ajeno al educando, sino que la forma de vida a la que se le quiere conducir ha de ser la solución de su propia vida (educar para la vida). El amor pedagógico exige la introyección en el niño y en sus disposiciones naturales, en las posibilidades de su educabilidad, siempre con referencia a su plenitud vital (Guardini, 2002, 65). En esta introyección aparecen íntimamente unidas la visión realista (objetividad) y la voluntad idealista (subjetividad) del acto educativo (Nohl, 1965, 20). Ahora bien, la voluntad de desarrollo sólo obtiene carácter educativo y espiritual cuando se busca el trato con un ser maduro para adquirir de él autonomía moral, la cual sólo puede conseguirse en el seno de una comunidad cultural (Nohl, 1968, 48; 1965, 232-233). En este sentido, la comunidad educativa es, al mismo tiempo, comunidad cultural y vital, y el desarrollo del espíritu del educando es la fuerza educadora más intensa. La formación del espíritu es el punto de partida de toda acción educativa, el supuesto básico de todo efecto pedagógico particular, hasta tal punto que toda metodología (medios o procedimientos) es, respecto al fin de la educación, absolutamente 
secundaria (los medios instruccionales dependen y se supeditan a los fines educacionales).

La comunidad educativa se apoya en dos grandes pilares: desde la perspectiva del educador, el amor y la autoridad; y, desde la perspectiva del educando, el amor y la obediencia. Estos dos pilares determinan la estructura propiamente pedagógica de la comunidad educativa centrada en la relación amorosa (intersección). La misión pedagógica central, conseguir una vida espiritual personal y social unitaria, exige del educador la comunidad de amor con el educando (Spiecker, 1984, 203-204). Sobre este amor se funda después la concentración por la obediencia respecto a la autoridad moral. Esta autoridad moral consiste en ser un modelo vicario (pathos o modelo de una forma superior de vida), que debe ser la imagen en la que se oriente y guíe el alumno para el desarrollo de su personalidad moral (Nohl, 1968, 51-53). Así pues, para Nohl la educación es una forma interior, una actitud espiritual y cultural vivida e históricamente contextualizada, que tiene por objeto el pleno desarrollo de la vida espiritual de los alumnos en el seno de una comunidad cultural unitaria (personalidad moral o êthos conforme al espíritu de la época). La educación del hombre precisa, necesariamente, de una relación pedagógica entre educador y educando en el seno de una comunidad educadora que es, al mismo tiempo, comunidad histórica, amorosa, cultural y vital centrada en el educando (ibidem, 186).

\subsection{La pedagogía como teoría comprensiva de la educación: la imposibilidad de una teoría científica de carácter naturalista}

Como hemos visto, la educación constituye una gran realidad objetiva que surge de la vida, de sus ideales y sus necesidades, constituyendo un sistema cultural relativamente autónomo, independiente de los sujetos que participan en él, y que está regido por una idea propia que actúa en toda acción educativa, y que sólo es comprensible y aprehensible en su desarrollo histórico (espíritu de la época). La teoría de la educación, la pedagogía, tiene que partir de esta realidad educativa en su doble aspecto de vivencia (valores culturales vividos por los sujetos) y de objetivaciones pedagógicas (contenidos educacionales que emanan de la cultura y que deben ser transmitidos a la nuevas generaciones). Para una correcta elaboración de la teoría de la educación se debe tomar como punto de partida la realidad educacional y la propia historia de la educación, las cuales se convierten en las fuentes para el conocimiento educativo (ibidem, 2931). Desde esta perspectiva, Nohl cuestiona, al igual que Dilthey, la posibilidad de que la pedagogía sea una ciencia naturalista (en sentido explicativo-causal), manifestando la imposibilidad de elaborar una teoría de la educación que posea validez general y que sirva para todo hombre y en cualquier momento histórico. Para Nohl es preciso crear la solución pedagógica para cada situación histórica. Básicamente, Nohl destaca tres grandes cuestiones que imposibilitan hablar de la pedagogía como una ciencia con validez general, es decir, como una pedagogía 
científica (siguiendo el modelo de las Ciencias de la Naturaleza), derivada de un único fin educacional con validez general (apriorístico, independiente de las variables espacio y tiempo):

- En primer lugar, Nohl señala $(1965,289)$ que las distintas posibilidades pedagógicas que resultan a lo largo de la historia se refieren a oposiciones en la cosmovisión del mundo, la vida y la cultura (Weltanschauung). En este sentido, la pedagogía se fundamenta en una actitud que emana de la propia visión que del mundo se tenga, determinando, consecuentemente, todos y cada uno de los actos y elementos educacionales (ibidem, 292). Por lo tanto, desde esta perspectiva, más que de pedagogía como ciencia de la educación, deberíamos hablar de pedagogías o teorías de la educación en plural (Nohl, 1968, 10), manifestando con ello las distintas posiciones que del acto educacional se han ido concretando a lo largo de la historia (Geisteshaltung), y que no son más que un reflejo de las distintas concepciones que del mundo, la vida y la cultura se han tenido. Las distintas teorías educacionales no serían otra cosa que formulaciones de actitudes pedagógicas básicas que estarían fundadas en diferentes posiciones respecto a la cultura, la vida y el mundo en un momento histórico determinado (Manen, 1978, 116-117).

- En segundo lugar, Nohl señala la multiplicidad de funciones pedagógicas que se le demandan a la educación y, por lo tanto, el problema que suponen las diferentes metas o finalidades teleológicas que se persiguen (grandes metas educacionales). Para Nohl, si se considera la realidad pedagógica en su evolución histórica, se perciben distintas y diferentes formas pedagógicas fundamentales, conteniendo cada una de ellas una finalidad ideal que exige su propia forma de relación pedagógica y sus propios medios educacionales (Nohl, 1968, 11). En el terreno más concreto y particular del acto educante desarrollado en la escuela, la pedagogía vuelve a ser diferente en función de las finalidades que se le propongan a la educación (Tenorth, 2002, 123). Según la forma dada a esta o aquella función educativa, es decir, según la finalidad educacional que se persiga, la forma pedagógica será muy diferente, y no hay, a su vez, posibilidad alguna de vencer las oposiciones que así surgen mediante una solución sistemática que satisfaga, de manera general y global, todas y cada una de las grandes finalidades que se le exigen a la educación en cada momento histórico. No es posible, por lo tanto, elaborar una teoría general de las distintas teorías concretas habidas en el decurso histórico.

- En tercer lugar, Nohl, al igual que Dilthey, señala la imposibilidad de establecer un fin para la educación que tenga validez general, con independencia del espacio y del tiempo histórico. Cuando se trata de los valores y de los fines vitales que deben servir de guía a la pedagogía, sólo se puede destacar un número limitado de verdades evidentes (principios 
inmediatos). Tales verdades o principios inmediatos no se hallan entre sí en una conexión viva y real al modo naturalista (ciencia), sino que adoptan la forma de un ideal (filosofía). No hay, por lo tanto, ningún sistema general del hombre y su educación, sino sólo una forma, una estructura teleológica que sólo será comprensible si se la contextualiza históricamente dentro de su marco cultural (hermenéutica), es decir, partiendo del contenido concreto de la experiencia particular que se viva (Wulf, 1999, 35-36). El concepto de perfección de una acción educativa está condicionado por las necesidades e ideales del momento histórico (Nohl, 1965, 16-17; 1968, 13-14). Así pues, para Nohl la pedagogía no es más que un arte, una intervención creadora en la vida individual.

Desde esta perspectiva, Nohl criticará los intentos de la pedagogía experimental por establecer procedimientos educacionales de validez general. Para vencer estas tres grandes dificultades que hemos señalado, nos dice Nohl (1968, 20), se ha admitido la no validez general de los fines de la pedagogía, separando, sin embargo, de la pedagogía general (de corte filosófico, Paulsen) otra parte más limitada, la pedagogía experimental (de corte naturalista, Lay y Meumann), también con pretensiones de validez general. La pedagogía experimental, nos dice Nohl, ya no se pregunta por los fines de la educación, sino por las vías experimentales para la consecución de los fines dados de la educación. El fundamento para ello debe darlo el análisis de los procesos psíquicos que constituyen la educabilidad del alumno. El conocimiento de los medios se apoya: por una parte, en la comprensión de la conexión causal que existe entre las disposiciones naturales y la influencia externa; y, por otra, en la comprensión de las leyes psicológicas del desarrollo madurativo de los educandos. Se trata de la naturalización de la pedagogía (Rincón, 2005). De esta forma, paralelamente a la técnica y a su fundamentación en las leyes naturales, también se desarrollará la técnica pedagógica. La magnitud de esta idea, sigue diciéndonos Nohl (1968, 21), es muy limitada ya que el técnico se enfrenta con la naturaleza externamente y, por lo tanto, puede investigarla independientemente de sus fines técnicos e imponer, posteriormente, dichos fines sobre la base de su conocimiento causal. Sin embargo, en el mundo educacional las cosas no funcionan así, pues en el alumno no se pueden separar los procesos anímicos de los fines a los que debe dirigirse su formación; el educando no es un mecanismo indiferente al que sólo tengamos que conocer para hacerlo funcionar correctamente: la educación es un proceso íntimo, interno, vivencial, teleológico y valorativo.

Según Nohl, la pedagogía experimental no contempla al educando como un ser humano, sino como una simple abstracción, como un dato estadístico, sin tener en cuenta que el educando siempre tiene una intencionalidad y una estructura teleológica orientada hacia fines espirituales. Los resultados de esta pedagogía experimental sólo serán válidos para la media general, informando sobre los alumnos en su conjunto, nunca sobre el alumno concreto al que, precisamente, debe dirigirse el acto educacional (ibidem, 22-23). Además, en este proceder 
pedagógico el fin de la educación queda en la oscuridad, ignorando la pedagogía experimental que los medios son inseparables de los fines a los que deben servir; y no sólo inseparables, sino que los medios deben escogerse, tal y como hemos visto, en función de los fines, nunca al revés. Si el hombre real es siempre el hombre con sus contenidos de valor, estos contenidos, que deben ser siempre educacionales, no se pueden separar del círculo de cultura en el que se desarrollan (Nohl, 1965, 51). Educar no es ninguna técnica, sino un arte creativo y creador, una acción cultural histórica, y la experiencia pedagógica debe ser también un arte, refiriéndose siempre a valores e ideales que influyen en toda manifestación docente y en todo procedimiento educativo (Nohl, 1968, 23-24; Montoya, 1956, 32-33). El ser humano en desarrollo siempre está en tensión entre la libertad y la necesidad (Nohl, 1965, 9), es decir, una cara de la moneda determinada causalmente (necesidad y explicación) y la otra comprensivamente (libertad e interpretación). La pedagogía experimental se siente autosuficiente para explicar la totalidad de la vida educacional, incluyendo aquellos actos provistos de sentido que sólo son comprensibles históricamente, bajo la luz de la interpretación (Nohl, $1968,25 ; 1965,26-27)$. Se trata de una gran equivocación, puesto que el hombre es un ser dual al que debemos acercamos por dos caminos diferentes: desde fuera, explicándolo, o desde dentro, comprendiéndolo. Si queremos ser coherentes, la pedagogía debe actuar según la naturaleza propia de la educación: explicándola y comprendiéndola (Nohl, 1965, 32). No obstante reconocer estas dos vías del conocimiento científico, lo cierto es que Nohl prioriza, fundamentalmente, la comprensión histórico-hermenéutica, alejándose de la materialidad empírica de la ciencia (Quintana, 1994, 148). El arte pedagógico se basa en un comportamiento pedagógico vivo, el cual se reduce, nos dice Nohl $(1965,292)$, al modo como el hombre se sitúe ante la vida.

\section{Wilhelm Flitner: la educación como un aRte y la pedagogía como la estética DE LA EDUCACIÓN}

Para Wilhelm Flitner la educación es una parte de la realidad vital, de la cual todos tenemos un concepto que obtenemos a través de nuestra actuación vivencial. Además, la educación es una actividad eminentemente responsable por lo cual es necesario que intervengan y colaboren hombres maduros que al actuar se consideren corresponsables de la educación, haciendo de ésta una relación ética. Por su parte, la ciencia pedagógica permanecerá, esencialmente, siempre como un filosofar dentro de la circunstancia histórica concreta de la educación, si bien plenamente independiente de dicho filosofar. La pedagogía no puede ser, en ningún caso, una ciencia positivista, sino comprensiva. Si la educación es un arte, la pedagogía sólo puede ser la teoría de ese arte, es decir, una estética de la educación. 


\subsection{La educación como actividad ética responsable y compartida}

Para Flitner delimitar claramente cuál es la realidad de la educación es una cuestión fundamental, no un simple problema teórico o especulativo, pues afecta a la propia esencia del hombre en tanto ser que actúa y que recibe actuaciones de otros hombres que viven en su mismo contexto histórico. En este sentido, y desde una perspectiva amplia y abarcadora, la realidad de la educación consistirá en toda actuación de la que pueda emanar una responsabilidad educacional (Flitner, 1972, 16-17); de hecho, toda la comunidad será, en sentido extenso, educadora. Ahora bien, el término educación puede ser usado en distintos sentidos. Así, puede designar la actividad y los efectos de la educación que, consciente o inconscientemente, imprime una persona sobre otra; también puede significar el acontecer educativo que una persona sufre o disfruta, el proceso educativo que en ella se realiza y, en términos generales, el resultado de dicho proceso. En su sentido activo, cuando se produce un efecto que repercute sobre lo íntimo, educar equivale a formar (formación educativa); en su sentido pasivo, significa el proceso en el decurso del cual la realidad íntima nace y se transforma (formación cultural). Desde esta perspectiva, para que podamos hablar estrictamente de educación debe presentarse una relación vital entre individuos que han de diferenciarse en sus distintas funciones (ibidem, 39-42): el educador y el educando. De aquí, precisamente, que no todo lo espiritual y cultural que la persona posee pertenezca, en sentido estricto, a la realidad educacional al no contemplarse la relación de mutua dependencia existente entre el educador y el educando. Esta dependencia representa una relación volitiva vital e intencional, cimentada en una relación ética responsable (Flitner, 1935, 36; 1972, 77), la cual se desarrolla en el marco de una comunidad educativa que ha alcanzado un consenso en asuntos pedagógicos que dota de sentido a todo el proceso educacional (Heinz-Elmar, 1990, 95).

Desde esta perspectiva, para Flitner (1935, 42-43), según concibamos al hombre (antropología) comprenderemos el fenómeno educacional; y, a la inversa, no es posible ninguna teoría del hombre si no se incluye la imagen de la realidad educacional como un aspecto fundamental de dicha teoría (Filosofía de la Educación). La antropología filosófica debe poner en claro el concepto del hombre y, por eso, cuando la pedagogía general trata del fenómeno educativo se convierte en una parte de la antropología filosófica. Por otra parte, cuando la pedagogía general se propone resolver su problema (la educación), debe atenerse a la totalidad de la antropología filosófica. Existe, pues, una relación mutua entre ambas direcciones, entremezclándose los problemas antropológicos con los pedagógicos (Runge y Muñoz, 2005, 347); de aquí, precisamente, que Flitner contraponga al positivismo la imagen histórica del mundo humano (historicismo). Según la misma, la sociedad de los seres humanos es concebida como una actividad ética y espiritual existente con ayuda de la educación (Flitner, 1980, 82). Para Flitner, todo lo espiritual deviene histórico y existe con ayuda de la memoria y de la tradición histórica: se edifica sobre la base de lo pasado y sin él es completamente incomprensible 
(Flitner, 1935, 55-56). La cultura, por lo tanto, es una forma de larga duración, con memoria y tradición, conservándose a lo largo del tiempo y, aunque sus estructuras son perecederas, siempre pueden ser regeneradas a través de hombres educados. Dos fenómenos de esta situación son fundamentales desde el punto de vista educacional (ibidem, 58): por un lado, la regeneración de los procesos de tradición de las formas culturales en las generaciones sucesivas (reproducción); y, por otro lado, la incorporación del individuo que se está desarrollando a las formas y al contenido del mundo objetivo-espiritual heredado históricamente (socialización).

Para Flitner (ibidem, 62), de las normas y contenidos espirituales se originan la enseñanza, la instrucción y la educación. Mediante la incorporación del individuo se renuevan las comunidades y, más allá de ella, se educan unas comunidades a otras. En este proceso, los educadores son servidores, órganos de las normas históricas, de sus tradiciones espirituales y de sus principales corporaciones e instituciones, con lo cual representan sus exigencias y hacen que sean eficaces. De ahí que Flitner defina la relación educativa como (ibidem, 65): "[...] la correlación entre el yo superior, racional y objetivo, y el yo mostrenco y común influido por el primero. El proceso espiritual de formación [...] se convierte [...] en la médula del fenómeno educativo". La influencia educativa se ejercita, por lo tanto, en el intercambio espiritual libre entre los portadores de la tradición y aquellos que se hallan sumergidos en la misma tradición y en las mismas normas, si bien de una manera menos vivaz y completa (Flitner, 1962, 27). La educación, en definitiva, es el proceso de crecimiento y maduración de los jóvenes dentro de unas etapas en las cuales los adultos protegen y fomentan el mencionado proceso (Sánchez y Ordóñez, 1997, 141). De este proceso de crecimiento y maduración es, precisamente, de lo que debe ocuparse la ciencia pedagógica, la pedagogía general (Flitner, 1935, 72).

\subsection{La ciencia de la educación como filosofía o estética de la educación}

Para Flitner la ciencia pedagógica tiene que ponerse al servicio de la vida de la educación, lo cual estará condicionado y subordinado a una determinada concepción sobre la esencia de la ciencia pedagógica, y determinará, consecuentemente, el rango de la pedagogía como ciencia. Se trata, por lo tanto, de representarnos de manera coherente qué sentido tienen la reflexión y el estudio de la educación. Según Flitner se pueden observar dos posicionamientos contrapuestos en su concepción y en sus resultados (ibidem, 13-17):

- $\quad$ Si se entiende que tales reflexiones parten del conocimiento del mundo y de la vida humana, y que, por lo tanto, como todo esfuerzo cognoscitivo, tienen su sentido en sí mismas, se constituye la ciencia pedagógica en una ciencia fáctica que, a base de métodos rigurosos, se encamina progresivamente hacia estados de saber cada vez más amplios. Además, 
si se entiende que la práctica educativa ha de llevarse a cabo guiada por este conocimiento, la pedagogía se convierte en una ciencia pragmática, sometida a la experiencia práctica, es decir, en un conjunto de reglas y principios que regulan la acción educativa (tecnología educacional). Como ciencia positiva de hechos la pedagogía tiene que describir objetivamente el sector que se ocupa de la educación, llegando a un acuerdo previo acerca de lo que es la educación. Ahora bien, según Flitner, lo que sea la educación queda indeterminado, pues ninguna descripción positiva de hechos puede averiguarlo. Desde planteamientos fácticos o positivistas tan sólo será posible atenerse a lo que ha representado auténticamente la educación en las distintas épocas y en los diferentes pueblos; sólo podrá investigar, por lo tanto, todo lo que atañe a la educación para conseguir abundante material susceptible de elaboración y sistematización que servirá a todas aquellas ciencias que se interesen por el problema educativo (ibidem, 15-16). Para Flitner, de esta investigación pedagógica de hechos no puede deducirse nunca una verdadera pedagogía (Vilanou, 2005, 185).

- Para su perfección interna la pedagogía debe ser considerada como una cuestión estética, siendo la filosofía quien la fundamente y quien establezca su estructura y alcance. La pedagogía es una actividad filosófica. Esta actividad debe penetrar toda la vida (global y sistémica) y ser guiada por la fuerza espiritual (ciencia espiritual). De ahí, precisamente, que la reflexión se halle en su fundamento, de la misma forma que se encuentra, inevitablemente, en la práctica como su parte integrante teórica (reflexión sobre la práctica, es decir, preocupación y ocupación). Mientras la educación se practique como un arte (Brezinka, 2002, 408), su conocimiento pertenece a la filosofía o, si se quiere, a la estética, pues todo arte debe engendrar de sí mismo una teorización con el fin de que pueda ser comprendido por los educadores. Por el simple hecho de que la educación se realiza como un hábito en el trato humano cotidiano, dicha meditación representa una reflexión que se verifica de manera directa en la vida y que se ejercita de forma ininterrumpida con el fin de que se conserven las normas y los postulados espirituales, de manera que sean un buen pertrecho para la vida (Flitner, 1970, 43-44). Este arte, que consiste en un conjunto de teorías que buscan apoyo en todas las esferas del pensamiento y en todas las ramas del saber, se eleva gradualmente al rango de una auténtica y rigurosa meditación filosófica, mediante la cual la reflexión se confirma a sí misma y se purifica ideológicamente (Flitner, 1935, 18-19). Si la pedagogía sigue esta dirección, con plena conciencia teórica, metódicamente y conforme a una planificación, llega a convertirse en pensamiento científico perteneciente a una de las Ciencias del Espíritu (ibidem, 19-20). 
Flitner, lógicamente, se postula en la dirección del segundo posicionamiento, es decir, en considerar la pedagogía como una de las ciencias comprensivas del espíritu. La ciencia pedagógica, esencialmente, debe permanecer siempre como un filosofar dentro de la circunstancia educativa, si bien como una parte independiente de dicho filosofar (ibidem, 21-22; Marptzlo, 1993, 85). La pedagogía, como ciencia del espíritu, según Flitner, ocupa un lugar intermedio entre la investigación positiva y el filosofar. Se encuentra en estrecha relación con el hábito y con la práctica y, por consiguiente, también con sus técnicas. Entre los hechos empíricos y las normas fundadas en la filosofía se encuentra un mundo intermedio en que se sitúa la acción educadora con su responsabilidad compartida. Por la unión del punto de vista empírico y del punto de vista especulativo se logra un tercer procedimiento, el hermenéutico-pragmático propio de la pedagogía comprensiva (Dräger, 2000, 80-81). Es hermenéutico porque se interpreta la vida vivida, se aprehende y esclarece el sentido educacional contenido en una realidad históricamente dada; es pragmático, en cuanto se refiere a la práctica y, consiguientemente, a la acción del hombre sobre el hombre (Künzli, 1999, 45). Lo que sea la educación sólo se puede alcanzar cuando uno mismo está poseído de voluntad educadora, es decir, de responsabilidad educacional (Flitner, 1966, 22-24; 1972, 16-18). En ello adquiere la ciencia pedagógica su significado, considerando el hábito y el arte educativos no solamente desde un punto de vista externo, sino también interno, susceptible de cambio y modificación.

Desde esta perspectiva, la pedagogía, nos dice Flitner $(1935,30)$, ha de ser una ciencia sistemática del espíritu, cuyo principal cometido es el de realizar una descripción, una representación de la circunstancia educativa y, con ello, del fenómeno de la educación dentro del cual pueda ser descubierto un sistema teórico coherente y sus correspondientes categorías pedagógicas (Vilanou y Otros, 1998, 69). El resultado de este procedimiento sistematizador y estructurador (Tusquets, 1957, 57-58) evidencia el carácter abstracto que tiene la pedagogía y, al mismo tiempo, su carácter práctico puesto que se manifiesta y realiza dentro de un marco histórico contingente, en una determinada situación histórica concreta (Vonken, 2005, 42). Con ello la pedagogía, cuyos límites, según Flitner (1935, 33), son indeterminables, efectúa el tránsito a los problemas de la pedagogía histórica y se convierte en un análisis de los problemas reales que siempre están determinados históricamente. El grado de verdad de la pedagogía reside en el enlace del tratamiento, a la vez, histórico y sistemático. En tanto se refiere al aspecto educativo de la existencia humana, la pedagogía debe intentar penetrar en el sentido y significado de la forma y el contenido de la vida real que siempre es histórica. Esta ciencia debe, además, dilucidar el hecho de la educación como tal, poniendo de relieve los aspectos particulares del fenómeno educativo. En este intento se ve claramente como el punto de partida de la pedagogía reside en una determinada situación histórica de la educación. La pedagogía parte del hecho de que todo el saber positivo de la realidad pedagógica ha de admitirse como procedente de un determinado campo histórico (ibidem, 35; De la Mora, 
1981, 269). Ahora bien, sólo se logrará la correcta elaboración de un pensamiento educativo si se ponen en relación los datos históricos, aportados por la pedagogía, con el hombre real inserto en su circunstancial vital, particular y concreta.

La ciencia pedagógica entendida como un filosofar o como una estética de la educación puede aportar a la práctica educativa dos cosas distintas (Flitner, 1935, 29-30): por una parte, el conocimiento concreto del fenómeno educativo; y, por otra, la formación pedagógica de los futuros profesionales de la educación. Si se trata de lo primero, el educador planteará sus problemas, a cuya solución concurrirán el psicólogo, el sociólogo y otros profesionales hasta donde el estado de su saber lo permita. Respecto al segundo punto, es evidente, nos dice Flitner (ibidem, 32), que se necesitan especialistas que hayan adquirido independientemente el nuevo saber pedagógico, que se interesen por la investigación misma y que se preocupen por su aplicación a la realidad de la vida educacional. Sin embargo, la formación pedagógica no consiste tan sólo en una transmisión de conocimientos teóricos, de resultados concretos obtenidos de la ciencia de la educación, sino que también debe ser un conocimiento real, armónico y coherente, un saber de la totalidad de la reflexión pedagógica dentro del conjunto existencial formado por los problemas derivados de la vida histórica (Carrillo, 1978, 153). De ahí, precisamente, que la formación de los futuros profesionales de la educación no pueda ser sólo fruto de un estudio profundo y de un riguroso pensamiento científico-espiritual, sino que debe ser posible, y hasta deseable, la participación del profano en la labor del especialista y que esta participación se integre con la completa formación pedagógica teórica, por lo cual es importante formar un cuerpo de educadores que profundicen en la ciencia pedagógica, y que, así formados, puedan dedicarse a la práctica de la educación.

\section{A MODO DE CONCLUSIÓN}

Eduard Spranger, Herman Nohl y Wilhelm Flitner desarrollarán pedagogías de corte culturalista, tomando a Dilthey como presupuesto de sus reflexiones pedagógicas. Unos y otros supeditarán y subordinarán la teorización pedagógicoeducativa a la reflexión filosófica, haciendo de la educación y de su ciencia un hecho trascendente, espiritual, estético, cuando no claramente metafísico o religioso, lo que lastrará, irremisiblemente, la posibilidad de una correcta conceptualización de lo educativo, es decir, de una verdadera teoría de la educación autónoma y de base científica, pues tal teoría será fruto de las concepciones filosóficas de cada uno de estos autores o, si se quiere, de sus creencias, ideologías y subjetividades (espiritualismo, idealismo crítico o neoidealismo kantiano), preocupándose mucho más por el trascendental tema de lo ontológico en educación (las grandes metas, finalidades y valores que el hombre debe desarrollar a través de la educación, es decir, el tipo de hombre ideal hacia el que debe dirigirse la educación), que por la realidad fáctica y material de la educación (saber para hacer, práctica, técnica y metodología, es decir, cómo conseguir en la realidad el tipo de hombre que se 
busca, así como la reflexión sobre las actuaciones realizadas). Todos estos autores acabaron confundiendo los campos propios de la Teoría de la Educación con los de la Filosofía de la Educación. Hoy sabemos que ambos campos son diferentes, aunque igualmente lícitos unos y otros; no obstante, la lección a aprender será que en un futuro la Filosofía de la Educación no vuelva a sustituir a los estudios teóricos sobre la educación.

\section{REFERENCIAS BIBLIOGRÁFICAS}

Abellán J. L. (1998) El exilio filosófico en América. Los transterrados de 1939. México, FCE.

Ali Jafella, S. (2006) Travesías filosóficas y sociales de la "Escuela Nueva" en Europa y en Estados Unidos. La Plata, Al Margen.

Álvarez, E. (2001) El saber del hombre. Madrid, Trotta.

Artigas, J. (1956) Contenido de la Historia de la Pedagogía. Revista de Estudios Políticos, 88, 75-88.

Basave, A. (1968) Filosofía del Quijote. Un estudio de antropología axiológica. México, Espasa-Calpe.

Betancourt, F. (2006) Teoría e Historia: los signos de una transformación. Observaciones a propósito del diálogo entre historiadores. Estudios de Historia Moderna y Contemporánea de México, 32, 103-125.

Bollnow, O. F. (1979) Sobre las virtudes del educador. Educación, 20, 48-58.

BrezinKa, W. (2002) Sobre las esperanzas del educador y la imperfección de la pedagogía. Revista Española de Pedagogía, 223, 399-414.

BRIE, R. J. (2000) Vida, psicología comprensiva y hermenéutica: una revisión de categorías diltheyanas. Pamplona, Servicio de Publicaciones de la Universidad de Navarra.

Carrillo, J. E. (1978) Ensayo sobre pedagogía general. La Paz, Gisbert.

Colom, A. J. (1978) Antropología y Educación. Mayurqa. Revista del Departament de Ciències Històriques $i$ Teoria de les Arts, 17, 303-309.

Colom, A. J. y Rincón, J. C. (2004) Epistemología neoidealista y fracaso fundacional del saber educativo. Teoría de la Educación. Revista Interuniversitaria, 16, 19-47.

Cruz, M. (1991) Filosofía de la historia. El debate sobre el historicismo y otros problemas mayores. Barcelona, Paidós.

De la Mora, J. G. (1981) Esencia de la Filosofía de la Educación. México, Editorial Progreso.

Díaz de Cerio, F. (1959) Dilthey y el problema del mundo histórico. Barcelona, Juan Flors Editor.

Dilthey, W. (1949) Fundamentos de un sistema de pedagogía. Buenos Aires, Losada.

- (1957) Historia de la pedagogía. Buenos Aires, Losada.

- (1978a) Introducción a las Ciencias del Espíritu. México, FCE (versión y prólogo de E. Imaz).

- (1978b) Teoría de la concepción del mundo. México, FCE (versión y prólogo de E. Imaz).

- (1978c) El mundo histórico. México, FCE (versión y prólogo de E. Imaz).

- (1978d) Psicología y teoría del conocimiento. México, FCE (versión y prólogo de E. Imaz).

Dräger, H. (2000) Zum Erscheinungswandel der Rationalität in der Pädagogik. Literatur-Und Forschungsreport Weiterbildung, 45, 73-83.

Dri, R. R. (1966) El concepto de educación en Spranger. Nordeste, 8, 81-101. 
EL LEGADO DE WILHELM DILTHEY: LAS PEDAGOGÍAS CULTURALISTAS

Espino, E. A. (2004) Semiótica y ética de la relación pedagógica. Educación y Educadores, 7, 213-220.

Ferraris, M. (2002) Historia de la hermenéutica. México, Siglo Veintiuno Editores.

Ferrater, J. (1979) Diccionario de Filosofía. Madrid, Alianza.

Fierro, A. (1993) Para una ciencia del sujeto. Barcelona, Anthropos.

Furtner, W. (1935) Pedagogía sistemática. Barcelona, Labor.

- (1962) El problema pedagógico de la libertad. Archivos de Ciencias de la Educación, 3 , 25-37.

- (1966) Das Selbstverständnis der Erziebungswissenschaft in der Gegenwart. Heidelberg, Quelle \& Meyer.

- (1970) La Educación y la vida. Educación, 2, 35-44.

- (1972) Manual de Pedagogía General. Barcelona, Herder.

- (1980) Is Education Morally Permissible? Western European Education, 12 (1), 80-88.

Gimeno, J. (2007) ¿De dónde viene la crisis de la profesión docente? Cuadernos de Pedagogía, 374, diciembre, 17-20.

Gotrgen, P. (1999) Christoph Wulf: le scienze dell'educazione in Germania. Educação \& Sociedade, vol. 20, 66 [Recurso electrónico: http://www.scielo.br/scielo.php?script=sci_ arttext\&pid=S0101-73301999000100010\&lng=in\&nrm=iso\&tlng=in. Consultado febrero, 2008].

Guardini, R. (2002) Las etapas de la vida. Su importancia para la Ética y la Pedagogía. Madrid, Ediciones Palabra.

Heinz-Elmar, T. (1990) El carácter general de la educación. Reflexiones desde la perspectiva de la Pedagogía. Revista de Educación, 292, 77-103.

Herrera, J. R. (2007) Filosofía de la vida e historicidad en Wilhelm Dilthey. Estudios de Filosofía Dialéctica e Historicista para la comprensión de la Realidad Latinoamericana [Recurso electrónico: http://www.scielo.br/scielo.php?script=sci_arttext\&pid=S0101-http:// jrherreraucv2000.blogspot.com/2007/07/filosofa-de-la-vida-e-historicidad-en.html. Consultado abril, 2009].

Hohmann, J. S. (1996) Contribuciones a la filosofía de Eduard Spranger. Berlín, Duncker \& Humblot.

Houssaye, J. (coord.) (2003) Cuestiones pedagógicas. Enciclopedia histórica. México, Siglo XXI.

Huergo, J. (2005) Hacia una genealogía de Comunicación/Educación. Rastreo de algunos anclajes político-culturales. La Plata, Editorial de la Facultad de Periodismo y Comunicación Social.

Iglesias, L. (2007) La cultura contemporánea y sus valores. Barcelona, Anthropos.

Kerschensteiner, G. (1926) Theorie der Bildung. Berlín, Leipzig.

KLAfKI, W. (1955) Dialektisches Denken in der Pädagogik, en Oppolzer, S. (ed.) Denkformen und Forschungsmetoden der Erziehungswissenschaft. München/Bonn, Ehrenwirth, 55-84.

KNelLer, G. F. (1963) Europaische Gesittung by Wilhelm Flitner. Internationale Zeitschrift für Erziehungswissenschaft, 9 (1), 116-117.

KüNZLI, R. (1999) German Didaktik: Models of Representation, of Intercourse, and of Experience, en Westbury, I.; Hopmann, S. y Riquarts, K. (eds.) Teaching as a Reflective Practice. The german didaktik tradition. Mahwah, NJ, Lawrence Erlbaum Associates, 41-53.

López, A. (1990) Comprensión e interpretación en las Ciencias del Espiritu. Murcia, Universidad de Murcia. 
Manen, M. Van (1978) Romantic Roots of Human Science in Education, en Willinsky, J. (ed.) Educational Legacy: Romanticism. Calgary, Calgary Institute for the Humanities, 115-140.

Marptzlo, W. (1993) Actualidad de la teoría de Wilhelm Flitner sobre la formación. Educación: Colección Semestral de Aportaciones Alemanas Recientes en las Ciencias Pedagógicas, 47, 84-95.

Martínez, M. (1989) El método hermenéutico-dialéctico en las ciencias de la conducta. Anthropos, 18, 85-111.

Merino, J. V. (2005) Pedagogía Social y Educación Social: Reto de acción y de comunicación para el Siglo XXI, en Ruz, J. (ed.) Pedagogía y Educación ante el Siglo XXI. Madrid, Universidad Complutense de Madrid, 225-254.

Montes, S. (2003) El valor de los bienes culturales clásicos, en Clásicos de la Pedagogía, 184, México, FES-Acatlán, 268-269.

Montovani, J. (1997) Educación y plenitud Humana. Buenos Aires, Ateneo.

Montoya, O. C. (1960) El problema epistemológico en la pedagogía contemporánea. San Luis, Editorial UNC.

NoHL, H. (1949) Die pädagogische Bewegung in Deutschland und ibre Theorie. Frankfurt.

- (1965) Antropología pedagógica. México, FCE.

- (1967) Introducción a la ética. Las experiencias éticas fundamentales. México, FCE.

- (1968) Teoría de la Educación. Buenos Aires, Editorial Losada.

Ortega, J. (2005) Pedagogía social y pedagogía escolar: La educación social en la escuela. Revista de Educación, 336, 111-127.

PÁez, F. (1988) El concepto de comprensión en W. Dilthey. Madrid, Universidad Complutense.

Quintana, J. M. ${ }^{a}$ (1994) Nohl, en Quintana, J. M. ${ }^{a}$ Educación social: Antología de textos clásicos. Madrid, Narcea, 147-172.

- (2000) El sociologismo pedagógico. Madrid, Síntesis.

Quintanilla, P. (2008) Comprensión, imaginación y transformación. Areté. Revista de Filosofía, vol. XX, 1, 111-135.

Reble, A. (1950) Theodor Litt. Stuttgart, Klett.

Rincón, J. C. (2005) Los primeros planteamientos epistemológicos en las Ciencias de la Educación: la herencia kantiana a través de las Ciencias de la Cultura. Taula, 39, 77-89.

Rorth, C. (2006) La Teoría crítica en la pedagogía alemana y su recepción en España. Madrid, Universidad de Alcalá de Henares.

Rojas, I. (2006) Presencia de los clásicos en la producción discursiva de pedagogía en la Facultad de Filosofía y Letras-UNAM. Perspectivas, v. 28, 113 [Recurso electrónico: http:// scielo.unam.mx/scielo.php?script=sci_arttext\&pid=\$0185-26982006000 300002\&lng=es\& nrm=iso. Consultado marzo, 2008].

Ropero, A. (1999) Introducción a la Filosofía. Una perspectiva cristiana. Barcelona, CLIE.

Rosales, L. (1959) Libertad y autenticidad. Revista de Estudios Politicos, 106, 35-72.

Rossi, P. (2006) Introducción, en WeBer, M. Ensayos sobre metodología sociológica. Buenos Aires, Amorrortu Editores, 9-37.

Roura-Parella, J. (1935) Spranger y las ciencias del espiritu. Madrid, Publicaciones de la Revista de Pedagogía.

- (1947) El mundo histórico social: ensayo sobre la morfología de la cultura de Dilthey. México, Biblioteca de Ensayos Sociológicos. Instituto de Investigaciones Sociales.

Rumié, S. (2008) Un modesto acercamiento temático: Dilthey y la Hermenéutica. Hermenéutica [Recurso electrónico: http://sebastianrumie.wordpress.com/2008/10/24/un-modesto-acercamiento-tematico-dilthey-y-la-hermeneutica/. Consultado diciembre, 2008]. 
Runge, A. K. y MuÑoz, D. A. (2005) Educación, formación, pedagogía y crisis de la modernidad: la reivindicación del ser humano como ser crísico, en Arellano, G. A. (coord.) La educación en tiempos débiles e inciertos. Barcelona, Anthropos, 343-376.

SaAvedra, M. S. (2004) Teoría cultural de la adolescencia. Eduard Spranger, en SaAvedra, M. S. Cómo entender a los adolescentes para educarlos mejor. México, Editorial Pax México, 13-14.

SÁncheZ, M. y Ordóñez, M. J. (1997) La educación en la sociedad multicultural. Papers, 53, 139-148.

Sarramona, J. (2000) Teoría de la Educación. Reflexión y normativa pedagógica. Barcelona, Ariel.

Savater, F. (1994) Invitación a la ética. Barcelona, Planeta-Agostini.

SCHeler, M. (1998) El saber y la cultura. Buenos Aires, Leviatán.

Schriewer, J. y KeIner, E. (1997) Pautas de comunicación y tradiciones intelectuales en las ciencias de la educación: Francia y Alemania. Revista Mexicana de Investigación Educativa, 2 (3), 117-148.

SPIECKER, B. (1984) The pedagogical relationship. Oxford Review of Education, 10 (2), 203-209.

Spranger, E. (1935) Psicología de la edad juvenil. Madrid, Revista de Occidente.

- (1946) Formas de vida. Psicología de ética de la personalidad. Buenos Aires, Revista de Occidente.

- (1947) Ensayos sobre la cultura. Buenos Aires, Argos.

- (1949) Cultura y Educación. Parte temática. Buenos Aires, Espasa-Calpe.

- (1958) El educador nato. Buenos Aires, Editorial Kapelusz.

- (1964) Espíritu de la escuela primaria. Buenos Aires, Editorial Kapelusz.

- (1966) Cultura y Educación. Parte histórica. Madrid, Espasa-Calpe.

TABORDA, S. (1951) Investigaciones pedagógicas. Córdoba, Editorial Assandri Deán Funes.

TENORTH,H.-E. (2002) HistorischeBildungsforschung, en Tippelt, R. Handbuch Bildungsforschung. Wiesbaden, VS-Verlag.

Teo, T. (2003) Wilhelm Dilthey (1833-1911) and Eduard Spranger (1882-1963) on the developing person. Humanistic Psychologist, 31 (1), 74-94.

Tusquets, J. (1957) Teoría de la crisis general de la educación. Convivium, II, 37-66.

Urdanoz, T. (1978) Historia de la Filosofía VI. De Bergson al final del Existencialismo. Madrid, Biblioteca de Autores Cristianos.

Valenzuela, A. (2004) Opciones epistemológicas y diseño curricular. Referencias para el currículum de formación de profesores. Perspectiva educacional, 44, 37-70.

Vázquez-Prada, M. ${ }^{a}$ T. (1972) Los grandes temas de la educación en Eduardo Spranger. Barcelona, Bayer.

Vergara, M. (1970) La figura del educador según Eduardo Spranger. Barcelona, Universitat de Barcelona (Tesis Doctoral. Material Manuscrito).

VIDAÑA, M. E. (2007) Valores universitarios en relación al Modelo Educativo UACJ Visión 2020. Avances, 153, 3-30.

Vilanou, C. (1998) Sobre la génesis y evolución de la pedagogía contemporánea. A propósito de la herencia kantiana. Revista Española de Pedagogía, 210, 246-262.

- (2001) De la Bildung a la Pedagogía Hermenéutica. Ars Brevis, 7, 255-279.

- (2002a) La pedagogía teológica en Edith Stein (1891-1942). Revista Española de Pedagogía, 223, 481-499.

- (2002b) Formación, cultura y hermenéutica: de Hegel a Gadamer. Revista de Educación, $328,205-223$. 
- (2004) Tres claves para una paideia hermenéutica (Dilthey, Heidegger y Gadamer), en Casanova, H. y Lozano, E. (eds.) Educación, Universidad y Sociedad: el vínculo crítico. Barcelona, Universitat de Barcelona, 43-72.

- (2005) Juan Roura-Parella (1897-1983) y los orígenes de la pedagogía universitaria en Cataluña, en Ruzz, J. (ed.) Pedagogía y Educación ante el Siglo XXI. Madrid, Universidad Complutense de Madrid, 171-201.

VILANOU, C. y otros (1998) Els orígens de la psicopedagogia a Catalunya. Barcelona, Universitat de Barcelona.

Villalpando, J. M. (1976) Filosofía de la Educación. México, Porrúa.

Vonken, M. (2005) Handlung und Kompetenz. Theoretische Perspektiven für die Erwachsenenund Berufspädagogik. Wiesbaden, VS Verlag für Sozialwissenschaften.

Wulf, C. (1999) Introducción a la ciencia de la educación. Medellín, Asonen.

Zamora, F. (2001) Comunicar y comprender. Bases hermenéuticas de la comunicación visual (primera parte). Imaggen. Revista de la Universidad Simón Bolívar, 54 (Tercer número especial dedicado a la investigación), 41-49.

Zubiri, X. (1982) Cinco lecciones de Filosofía. Madrid, Alianza. 